\title{
First report of Symphoromyia immaculata (Diptera: Rhagionidae) from Italy, with the description of its attack and blood-feeding behaviour on human hosts
}

\author{
F. Romiti, ${ }^{1}$ C. De Liberato, ${ }^{1}$ A. Magliano, ${ }^{1}$ A. Ermenegildi, ${ }^{1}$ I. Del Lesto, ${ }^{1}$ P. Beuk ${ }^{2}$ \\ ${ }^{1}$ Laboratory of Parasitology and Entomology, Istituto Zooprofilattico Sperimentale del Lazio e della Toscana M. \\ Aleandri, Rome, Italy; ${ }^{2}$ Natuurhistorisch Museum Maastricht, Maastricht, the Netherlands
}

\begin{abstract}
Specimens from a swarm of Symphoromyia immaculata (Meigen, 1820) were collected in the act of biting people in a farmhouse in Central Italy. The species is distributed in West and Central Europe and eastwards in Northwest Russia. This is the first record of $S$. immaculata in Italy, with a documented case of humans suffering from bites of this species.
\end{abstract}

\section{Introduction}

Snipe flies (family Rhagionidae) are 4.5 to $15.0 \mathrm{~mm}$ long stout bodied flies, with members from Palearctic, Nearctic, Neotropical

\footnotetext{
Correspondence: Federico Romiti, Laboratory of Parasitology and Entomology, Istituto Zooprofilattico Sperimentale del Lazio e della Toscana M. Aleandri, via Appia Nuova 1411, 00178 Rome, Italy. Tel.: +39.06.79099306.

E-mail: federico.romiti.86@gmail.com
}

Key words: Tabanoidea, Rhagionidae, blood-sucking fly, Symphoromyia, Umbria, Italian fauna.

Contributions: The authors contributed equally.

Conflict of interest: The authors declare no potential conflict of interest.

Funding: None.

Received for publication: 18 August 2020.

Revision received: 26 March 2021.

Accepted for publication: 18 May 2021.

${ }^{\circ}$ Copyright: the Author(s), 2021

Licensee PAGEPress, Italy

Journal of Entomological and Acarological Research 2021; 53:9315 doi:10.4081/jear.2021.9315

This article is distributed under the terms of the Creative Commons Attribution Noncommercial License (by-nc 4.0) which permits any noncommercial use, distribution, and reproduction in any medium, provided the original author(s) and source are credited. and Australian regions (Smith, 1993; Hoy \& Anderson, 1978). Rhagionidae represent a basal family within the Tabanomorpha, with most species preying on other insects or feeding on nectar, honeydew and pollen (Grimaldi \& Engel, 2005; Oosterbroek, 2006). Species of the Symphoromyia Frauenfeld, 1867 and Spaniopsis Senior-White, 1914 genera are known to be bloodfeeders (Colless \& McAlpine, 1991; Mullen \& Durden, 2009). Being the only mandibulate members of Rhagionidae, these genera possess piercing and sucking mouthparts similar to those of Tabanidae (Figure 1A) (Snodgrass, 1944; Kerr, 2010). Only adult females seek for and bite hosts, needing a blood meal to produce eggs (Hoy \& Anderson, 1978). Symphoromyia spp. are also wellknown swarmers, approaching and attacking in groups (Shemanchuk \& Weintraub, 1961), although some species can alight singly on the host (Knab \& Cooley, 1912). References of attacks on livestock, wild animals and humans have been reported, since first original observations by Osten-Sacken (1877), from USA and Canada (Knab \& Cooley, 1912; Aldrich, 1915; Shannon, 1915; Shemanchuk \& Weintraub, 1961; Hoy and Anderson, 1978;). Host range is a neglected aspect of Symphoromyia spp. biology, but it is reported to be wide for certain species and narrow for others. Reported hosts include horses (Aldrich, 1915; Hearle, 1928), cattle (Shemanchuk \& Weintraub, 1961), dogs (Frohne \& Williams, 1951) and deer species (Hoy \& Anderson, 1978).

Although Symphoromyia species can be considered insects of minor medical importance, not being proven vectors of any disease (Smith, 1993; Kerr, 2010), several species were recorded as occasional human biters (e.g., Knab \& Cooley, 1912; Chvála, 1983). Considerable individual variation was highlighted in reaction to Symphoromyia bites, ranging from mildly annoying to very painful, with cases of severe inflammation, swelling reactions and itching (reviewed by Turner, 1979). Typically, individuals alight silently on host wrists, palms and neck and, after a quite rapid engorging time, leave a wound from which a small drop of blood may ooze (Knab \& Cooley, 1912; Aldrich, 1915; Mills, 1943; Hoy \& Anderson, 1978).

Mills (1943) pinpointed that Symphoromyia spp. would be restricted to higher elevations (900-1500 m a.s.1.), confirming previous findings (Knab \& Cooley, 1912). The genus has a wide distribution in Europe, ranging from Spain to Northwest European Russia, and includes three species: Symphoromyia immaculata (Meigen, 1820), Symphoromyia melaena (Meigen, 1820) and Symphoromyia crassicornis (Panzer, 1806) (Majer et al. 2013). These last two species are reported from Italy (Stoch \& Minelli 2003). Knowledge about occurrence and distribution of Italian 
snipe flies species is mainly due to the works by Bezzi (1892, $1893,1894,1895,1898,1918)$. To date, there is no published record of $S$. immaculata in Italy, neither on the occurrence of any Symphoromyia species across Umbria region. Besides reporting for the first time the occurrence of S. immaculata in Italy and providing data to extend its distribution, we describe the first case report of this snipe fly attacking humans in Italy.

\section{Case report}

Four guests of a farmhouse in Northern Umbria $\left(43.440278^{\circ} \mathrm{N}\right.$, $12.187222^{\circ} \mathrm{E}$; Monte Santa Maria Tiberina Municipality, Perugia Province) were annoyed by a swarm of flies at sunset (6:00-8:00 $\mathrm{pm}$ ) on the $28^{\text {th }}$ of June 2020 . The farmhouse is located on a wooded hill (660 $\mathrm{m}$ a.s.1.), characterized by mixed-oak forest and cultivated fields. Nine flies from the swarm were captured and brought to the Laboratory of Entomology of the Istituto Zooprofilattico Sperimentale del Lazio e della Toscana "M. Aleandri" (IZSLT) for species identification. When interviewed by IZSLT entomologists, the guests told about a large swarm of dozens of individuals, which resulted particularly annoying at first, as they flew close to the face and arms. Shortly after the approach, flies started alighting on the hosts and some of them were collected in the act of biting. Only one case of complete engorgement was described, characterized by the presence of a drop of blood at the wound, followed by a mild pain and swelling. Specimens were identified morphologically as females belonging to the genus Symphoromyia, according to the description of this genus and morphological key (Figure 1B) (Séguy, 1926; Stubbs \& Drake, 2001; Stoch, 2003; Turner, 1974). Since in the farmhouse a Horse-Pal trap not lured with any chemical was active to catch horseflies (Tabanidae) in proximity of a swimming pool, in order to protect guests, Authors asked the owners to provide the content of the trap. Together with hundreds of horseflies, 11 Symphoromyia sp. females were found in the trap. Interestingly, in the following days and weeks none at the farmhouse experimented attacks by these flies, even during days characterized by meteorological conditions similar to those when the attack occurred (average relative humidity: 57\%, average temperature: $23^{\circ} \mathrm{C}$, average wind speed: $8 \mathrm{~km} / \mathrm{h}$ ).

\section{Notes on taxonomy and identification}

The genus Symphoromyia includes stout bodied snipe flies (4.7 to $9 \mathrm{~mm}$ ) with Holarctic distribution (Kerr, 2010). The genus is characterized by the autapomophic scape enlargement: always elongate and clearly longer than pedicel (Kerr, 2010). The scape can be extremely elongate and wide, more than five times longer than the second antennomere as in $S$. crassicornis and $S$. hirta (Séguy, 1926; Kerr, 2010). The third antennomere is always kidney-shaped or subcircular; the arista insertion is in the dorsoapical
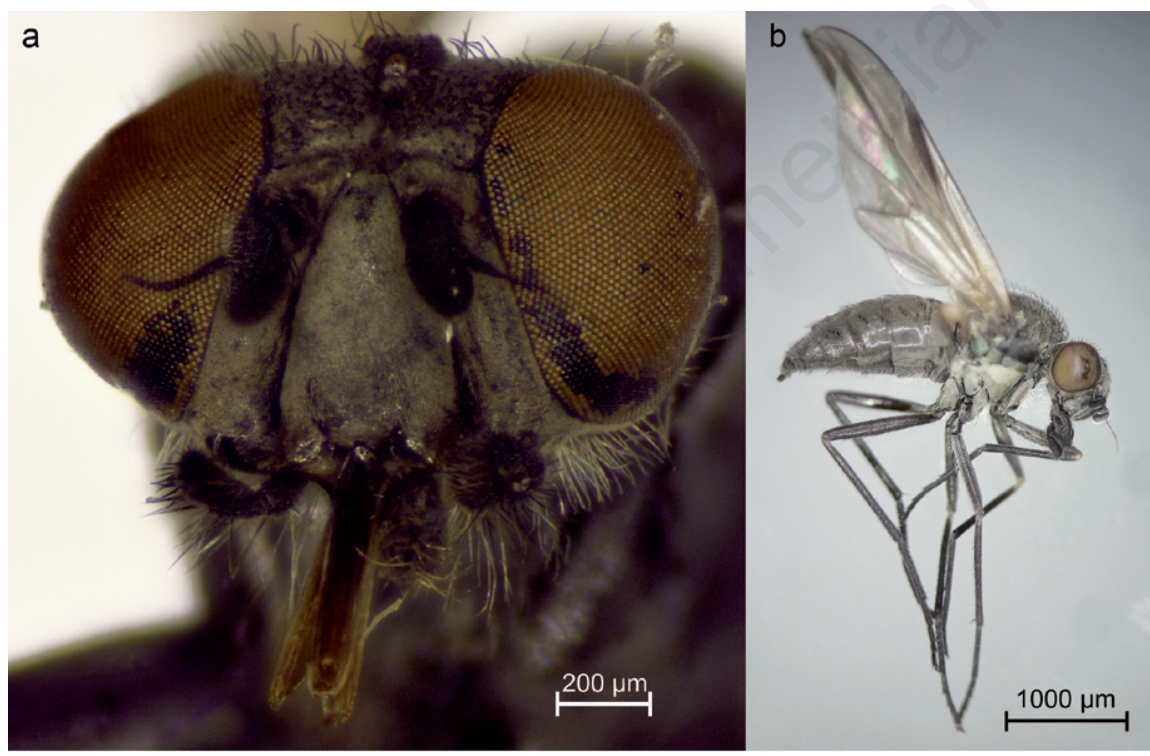

C

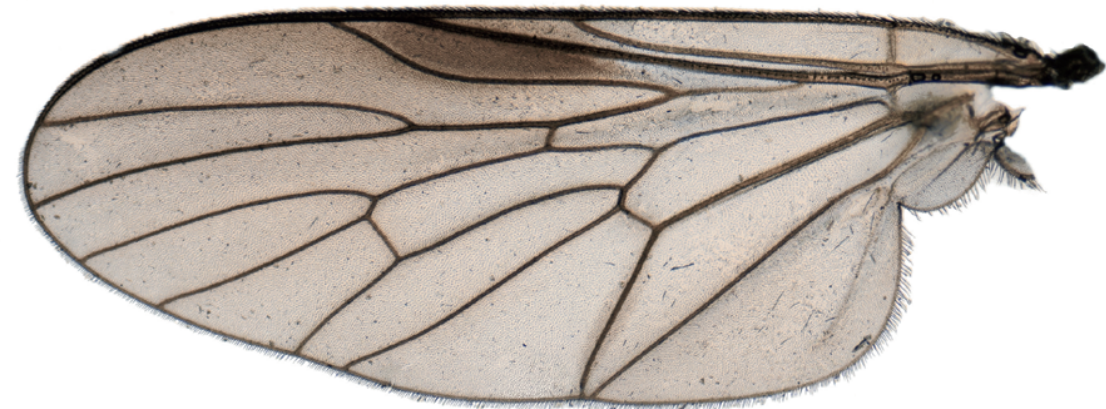

$1 \mathrm{~mm}$

Figure 1. Symphoromyia immaculata: female A) head, B) whole specimen and C) wing. 
portion of the third antennomere; mandibles are present. The open anal cell present in Symphoromyia was used by Frauenfeld (1867) to distinguish this genus from the closely related genera Atherix and Ptiolina. In the West Palaearctic two subgenera are recognised. Parasymphoromyia Becker, 1921 with only one West Palaearctic species ( $S$. crassicornis) can be recognized by the strongly swollen scape. The remaining two West Palaearctic species are members of the subgenus Symphoromyia s.s. and has a slender scape.

The identity of the collected specimens needed some further investigation. The slender scape clearly placed them in the nominate subgenus. Generally, the two species are distinguished by the extend of darkening of the wings (see for example Rozkošný \& Spitzer, 1965): S. immaculata with wings that are clear to slightly greyish without distinct markings or pterostigma and S. melaena with extensively darkened wings in which the pterostigma is black. Our specimens, however, have barely darkened wings but still the pterostigma is clearly dark and this leads to confusion. An extensive search through various resources showed that the degree of darkening of the pterostigma in S. immaculata seems to vary but that the costa and the base of the radial veins in the wings is always yellowish to brownish. The membrane of the wing itself is at most light greyish except for (sometimes) the pterostigma. The veins at the base of the wings in $S$. melaena are always black and the wing surface is darkened considerably at least on the anterior half of the wing. Within this darkened area there always is a narrow whitish or pale streak just posterior of vein $\mathrm{R}_{1}$. No trace of such a streak is visible in the wing $S$. immaculata. The absence of this streak and the yellowish-brown veins at the base of the wing in our specimens clearly show they belong to $S$. immaculata (Figure 1C).

\section{Discussion and Conclusions}

This is the first report of S. immaculata for Italy. To date the species occurs in 11 European Countries and has been reported from three (out of four) states bordering Italy (French mainland, Switzerland and Austria). Together with our report, the occurrence in Bosnia and Herzegovina represents the southernmost extreme of its distribution, while Great Britain and the Northwestern Federal district of Russia define its northernmost limit (Majer et al., 2013). To the best of our knowledge, this is the second report of flies of the genus Symphoromyia attacking people in Italy, being the first one dated back to a century ago (Luigioni, 1921). Furthermore, our finding enlarges the known distribution of this genus in our Country. As Symphoromyia is a poorly known and studied group of haematophagous insects, main aim of the present report is increasing awareness among medical entomologists of their presence and the possibility that snipe flies may attack humans. Thus, they should be considered when trying to ascertain the responsible of attacks to people, even considering that cases of hypersensitive response to Symphoromyia sp. bites were previously reported (Shemanchuk \& Weintraub, 1961; Turner, 1979). Lack of similar reports in Italy induces thinking that such an event has to be considered rare and that Symphoromyia spp. prefer to feed on other hosts, in the present case the more probable one being roe deer (Capreolus capreolus) (Hoy \& Anderson, 1978), very abundant in the area around the farmhouse. Nonetheless, we have to take into account that number of attacks to human could have been underestimate due to the lack of knowledge on snipe flies. Furthermore, snipe flies seemed to be active for few days and not very abundant, considering also the little number of specimens sampled by the Horse-Pal trap. Despite the small number, the finding of some specimen in this trap could mean that, as the other Tabanomorpha, Symphoromyia females seek hosts by sight. In accordance to what previously reported for other Symphoromyia species, these flies appear to form swarms around the hosts and - as pointed out by a guest of the farmhouse - leave a wound from which a small drop of blood may flow (Mills, 1943; Shemanchuk \& Weintraub, 1961). Even considering that the attack occurred at lower altitude respect to what formerly reported (Knab \& Cooley, 1912; Mills, 1943; Kerr, 2010), our case confirmed the preference of Symphoromyia snipe flies to mountainous places. Besides, adult phenology of flies of this genus, previously indicated as most active during summer months (Turner, 1979; Kerr, 2010) is confirmed. Given the troublesome nature of snipe flies (e.g., noxious swarms, hypersensitive responses), further investigations are needed to better understand their ecology, paying particular attention to larval habitat preferences, to reduce population and avoid swarms when it is deemed necessary.

\section{References}

ALDRICH J.M., 1915 - The dipterous genus Symphoromyia in North America. - Proc. U.S. Nat. Mus. 49: 113-42.

BEZZI M., 1892 - Contribuzione alla fauna ditterologica della provincia di Pavia. - Boll. Soc. Ent. It. 24: 97-151.

BEZZI M., 1893 - I Ditteri del Trentino. Saggio delle specie di Ditteri finora raccolte in Trentino. - Atti Soc. Ven. Trent. Sc. Nat. 2: 207-272.

BEZZI M., 1894 - I Ditteri del Trentino. Saggio delle specie di Ditteri finora raccolte in Trentino. - Atti Soc. Ven. Trent. Sc. Nat. 2: 274-352.

BEZZI M., 1895 - I Ditteri della Calabria. - Boll. Soc. ent. It. 127: 39-78

BEZZI M., 1898 - Contribuzioni alla fauna Ditterologica italiana. II. Ditteri delle Marche e degli Abruzzi. - Boll. Soc. ent. It. 30: 19-50.

BEZZI M., 1918 - Studi sulla ditterofauna nivale delle Alpi italiane. - Mem. Soc. It. Sc. nat. Mus. civ. St. nat. Milano. 9: 1-164.

CHVÁLA M., 1983 - First record of blood-sucking in palaearctic Rhagionidae (Diptera), with description of a new Symphoromyia of the crassicornis-group from Central Asia. Acta Entomol. Bohemoslov. 80: 423-436.

COLLESS D.H., MCALPINE, D.K., 1991 - Diptera. In: Insects of Australia. - Melbourne University Press, Melbourne: 717$789 \mathrm{pp}$.

FRAUENFELD G. R. VON, 1867 - Zoologische Miscellen XI. Verh. Zoo1. Bot. Ges. Wien. 17: 425-502.

FROHNE W.C., WILLIAMS R.B., 1951 - Notes on snipe flies of the genus Symphoromyia in Alaska. Mosq. News. 11: 32-33.

GRIMALDI D., ENGEL M.S., 2005 - Antliophora: Scorpionflies, Fleas, and True Flies. Evolution of the Insects. - Cambridge University Press: 468-547 pp.

HEARLE E., 1928 - Insects of the season 1928 in British Columbia. Insects affecting livestock and man. 59th Ann. Rep. Entomol. Soc. Ont.- Toronto: 128 pp.

HOY J., ANDERSON J., 1978 - Behavior and reproductive physiology of blood-sucking snipe flies (Diptera: Rhagionidae: Symphoromyia) attacking deer in northern California. Hilgardia. 46: 113-168.

KERR P.H., 2010 - Phylogeny and classification of Rhagionidae, with implications for Tabanomorpha (Diptera: Brachycera). Zootaxa. 2592: 1-133.

KNAB F., COOLEY R.A., 1912 - Symphoromyia as a blood-sucker. - Proc. Entomol. Soc. Wash. 14: 161-62.

LUIGIONI P., 1921 - Una notevole invasione di "Symphoromyia 
grisea Meigen", a Fiuggi Fonte (Prov. di Roma). Atti Accad. Pontif. Nuovi Linceri, Rome.

MAJER M., BYSTROWSKI C., RICHTER V.A., 2013 - Fauna Europaea: Symphoromyia Frauenfeld, 1867. Fauna Europaea version 2017.06, https://fauna-eu.org/cdm_dataportal/taxon/ 98aaa957-28cd-4bbe-ac13-77e58de78383 [- date accessed: 26 March 2021]

MILLS H.B., 1943 - An Outbreak of the Snipe Fly Symphoromyia hirta. - Journal of Econ. Entomol. 36: 806.

MULLEN G.R., DURDEN L.A., 2009 - Medical and veterinary entomology. Academic press: 792 pp.

OOSTERBROEK P., 2006 - The European Families of the Diptera: Identification Diagnosis Biology. Brill.

OSTEN-SACKEN C.R., 1877 - Western Diptera: Descriptions of new genera and species of Diptera from the region west of the Mississippi and especially from California. - Bull. U.S. Geol. Sur. Terr. 3: 189-354.

ROZKOŠNÝ, R., SPITZER K., 1965 - Schnepfenfliegen (Diptera, Rhagionidae) in der Tsjechoslowakei. Acta Entomol. Bohemoslov. 62(5): 340-368.

SÉGUY E., 1926 - Faune de France 13. Diptères (Brachycères): Stratiomyiidae, Erinnidae, Cœænomyiidae, Rhagionidae, Tabanidae, Codidae, Nemestrinidae, Mydaidae, Bombyliidae, Therevidae, Omphralidae. P. Lechevalier: 308 pp.

SHANNON R.C., 1915 - Eastern Symphoromyia attacking man. Proc. Entomol. Soc. Wash. 17: 188-189.

SHEMANCHUK J.A., WEINTRAUB L., 1961 - Observations on the biting and swarming of snipe flies (Diptera:
Symphoromyia) in the foothills of southern Alberta. - Mosq. News. 21: 238-243.

SMITH K.G.V., 1993 - In: LANE R.P., Insect of minor medical importance. - Crosskey R.W. (eds), Medical Insects and Arachnids. Springer, Dordrecht.

SNODGRASS R.E., 1944 - The feeding apparatus of biting and sucking insects affecting man and animals. - Smithsonian Miscellaneous Collections.

STOCH F., 2003 - CK2000. Checklist of the species of the Italian Fauna. On-line version 2.1

STOCH F., MINELLI A., 2003 - The project "Checklist of the species of the Italian fauna". Atti Convegno "La conoscenza botanica e zoologica in Italia: dagli inventari al monitoraggio", Università di Roma "La Sapienza", 14 dicembre 2001, Ministero dell'Ambiente e della Tutela del Territorio: 5-15.

STUBBS A.E., DRAKE C.M., 2001 - British soldierflies and their allies: an illustrated guide to their identification and ecology: covering all flies (Diptera) in the families Acroceridae, Asilidae, Athericidae, Bombyllidae, Rhagionidae, Scenopinidae, Stratiomyidae, Tabanidae, Therevidae, Xylomyidae and Xylophagidae. British Entomological and Natural History Society.

TURNER W.J., 1974 - A revision of the genus Symphoromyia Frauenfeld (Diptera: Rhagionidae): I. Introduction. Subgenera and species-groups. Review of biology. Can. Entomol. 106: 851-868.

TURNER W.J., 1979 - A case of severe human allergic reaction to bites of Symphoromyia (Diptera: Rhagionidae). - J. Med. Entomol. 15: 138-139. 